九州大学学術情報リポジトリ

Kyushu University Institutional Repository

\title{
Identification of CNT Growth Region and Optimum Time for Catalyst 0xidation: Experimental and Modelling Studies of Flame Synthesis
}

N. Hamzah

High Speed Reacting Flow Laboratory (HiREF), Universiti Teknologi Malaysia

M. F. Mohd Yasin

High Speed Reacting Flow Laboratory (HiREF), Universiti Teknologi Malaysia

M. Z. M. Yusop

Advance Membrane Technology Research Centre, Universiti Teknologi Malaysia

M. T. Zainal

High Speed Reacting Flow Laboratory (HiREF), Universiti Teknologi Malaysia

他

https://doi.org/10.5109/2328409

出版情報 : Evergreen. 6 (1)，pp.85-91，2019-03. 九州大学グリーンアジア国際リーダー教育センター バージョン：

権利関係 : 


\title{
Identification of CNT Growth Region and Optimum Time for Catalyst Oxidation: Experimental and Modelling Studies of Flame Synthesis
}

\author{
N. Hamzah ${ }^{1}$, M.F. Mohd Yasin ${ }^{1 *}$, M.Z.M. Yusop², M.T. Zainal ${ }^{1}$, M.A.F. Rosli ${ }^{1}$ \\ ${ }^{1}$ High Speed Reacting Flow Laboratory (HiREF), Universiti Teknologi Malaysia, 81310 Johor Bahru, Johor, \\ Malaysia \\ ${ }^{2}$ Advance Membrane Technology Research Centre, Universiti Teknologi Malaysia, 81310 Johor Bahru, Johor, \\ Malaysia
}

*Author to whom correspondence should be addressed, E-mail: mohdfairus@mail.fkm.utm.my

(Received January 31, 2018; accepted March 26, 2019).

\begin{abstract}
Control improvement of carbon nanotubes synthesis in flames requires synergistic computational and experimental studies. The present study investigated distribution of carbon nanotubes growth region within methane diffusion flame using acid dipped nickel wire. The carbon nanotubes growth occurred in a narrow range between 4 to $6 \mathrm{~mm}$ height above the burner. Nickel wire oxidation in nitric acid within 90 seconds to 260 seconds favors formation of carbon nanotubes. Prediction of the carbon nanotubes growth region using multi-scale modelling method achieved a reasonable agreement with the experimental results though the region of no growth was not reproduced due to the exclusion of soot formation modelling.
\end{abstract}

Keywords: carbon nanotubes, flame synthesis, diffusion flame, model.

\section{Introduction}

Flame synthesis is an alternative synthesis technique for carbon nanotubes (CNT) which has significant potential to revolutionize the conventional CNTs synthesis process. Theoretically, CNT synthesis using flame capable of producing CNTs with a fraction of the cost of catalytic chemical vapor deposition (CCVD) process due to its highly energy efficient process. Auto-thermal conditions in flame generate rapid CNT synthesis process compared to the CCVD which reduced the energy consumption of the process considerably, hence reducing the overall cost of the CNTs production $^{1-3}$. These compelling fundamental characteristics of flame synthesis process have driven the research in flame synthesis of CNT for the last three decades $^{1}$. As the demand for CNTs in the world market continues to increase each year, the search for the ideal synthesis process for producing cheaper CNTs remains strong ${ }^{4}$. Significant numbers of research groups are still active in exploring new possibilities to manipulate the advantages of flame based synthesis process in producing $\mathrm{CNTs}^{5-13}$.

In general, the combustion process in flame produces all the important parameters for CNT synthesis to occur; continuous supply of carbon source, a suitable temperature for hydrocarbon molecules dissociation and nanotube formation. With the presence of suitable transition metal catalysts such as nickel, iron or cobalt, CNTs formation in flame occurred through three main stages; carbon deposition by surface catalysis, carbon diffusion and transport, and carbon precipitation ${ }^{1}$. In literature, experimental studies focus on several important parameters; flame configuration, reactant type and composition, growth region and catalyst. CNTs have been successfully produced in various combination of flame configuration, fuel type, and oxidizer concentration, with each combination of flame configuration and reactant have significant effects on the morphology and growth rate of the CNTs ${ }^{1}$.

Methane co-flow diffusion flame was first used synthesize CNTs by Saito's group in early $2001^{14}$. Using co-flow diffusion flame burner, bundles of multiwalled CNTs (MWNT) are synthesized on top of Ni-Cr wire $(60 \% \mathrm{Ni}, 25 \% \mathrm{Cr}, 14 \% \mathrm{Fe})$ when exposed in the flame with the wire attached to stainless steel wire mesh ${ }^{14}$. Saito's work explored the effect of sampling location toward diameters of MWNT. Plus, pre-oxidized Ni-Cr in nitric acid was found to produces relatively aligned MWNTs compared to the wires without acid oxidation ${ }^{14}$. In later works, another research group formulated steps of MWNTs formation in methane diffusion flame and theorized the creation of tabular and bamboo type of MWNTs $^{15}$. Later, Li et al. compared CNTs produced 
using two types of methane diffusion flame, co-flow and counter diffusion flame ${ }^{16}$. Using nickel alloy as substrate/catalyst, it was found that CNTs are formed only at a certain range of temperature in methane flame. In more recent work, Hou et al. utilized methane jet diffusion flame to monitor the effect of acoustically modified fuel jet supply toward the formation of CNTs in methane flame ${ }^{17}$.

Despite various experiments that have been carried out to analyze the synthesis process of CNTs in flame, there is very limited progress to further enhance understanding of CNTs growth in flame through a combination of comprehensive experimental and modelling works ${ }^{1,18}$. Besides experimental works, accurate modelling of flame synthesis is vital to enhance our understanding and development of the process. Multiscale modelling is needed to study chemical process that happens at different time scale ${ }^{19-21}$. Initial work on CNTs growth modelling in CCVD synthesis was pioneered by Endo et al. that determined the reaction rate for carbon deposition on the catalyst substrate through the predicted distribution of temperature and species in the furnace ${ }^{22}$. Later, Kuwana and Saito introduced particle dynamic equation to predict CNTs formation using CFD simulation result of a CCVD chamber ${ }^{19}$.

Here, initial work on CNTs synthesis using methane co-flow diffusion flame on top of oxidized pure nickel wire as catalyst are reported. Nickel wire was used since only nickel pure and nickel alloy wire has been recorded in literature to producing CNTs in methane flames $^{14-17,23-27}$. The catalyst was oxidized in nitric acid at a pre-determined period to explore the effect of acid dipping duration towards the formation of CNTs. Effect of height above burner (HAB) of the catalyst was also explored by exposing the wires into the flame in one millimeter increment above the burner. Besides experimental works, we also performed simulations analysis of the CNTs synthesis process by utilizing reconfigured multiple-scale modelling to suit the burner configuration $^{20}$. A numerical model that represents the distribution of temperature and species in the flame is used to predict CNTs growth region within the flame. The predicted growth regions are compared to the actual result of the experiments for validation.

\section{Experimental Details}

In the present study, the CNTs were synthesized using impact flow sampling, where catalyst wire attached to a wire mesh was inserted directly into the flame ${ }^{25}$. Fig.1 shows a schematic of the experimental flame apparatus. A methane diffusion flame was established at the exit of $18 \mathrm{~mm}$ diameter stainless steel tube which pure methane (99.9\% purity) flowed at a rate of $0.48 \mathrm{slpm}$. The central tube was surrounded by $24 \mathrm{~mm}$ diameter concentric stainless-steel tube where the mixture of pure nitrogen (99.9\%) and oxygen (99.9\%) flows at the total rate of 4 slpm, controlled by two separate Honeywell ${ }^{\odot}$ flow sensors. The mixture ratio of the nitrogen and the oxygen was set to 3:1. Mixture of nitrogen and oxygen were to ensure a controlled environment within the flame region with a known composition of fuel and oxidizer. A steady and stable methane diffusion flame was established on the burner port with a visible flame height of $100 \mathrm{~mm}$. All syntheses process was performed at atmospheric pressure within a burner enclosure. The burner enclosure consists of a viewing panel and constant speed extractor fan to ensure minimum disturbance of the surrounding air toward the established flame. The temperature of the flame was measured using a B type thermocouple made of platinum- $6 \%$ rhodium and platinum-30\% rhodium unsheathed wires with 0.5 $\mathrm{mm}$ bead head.

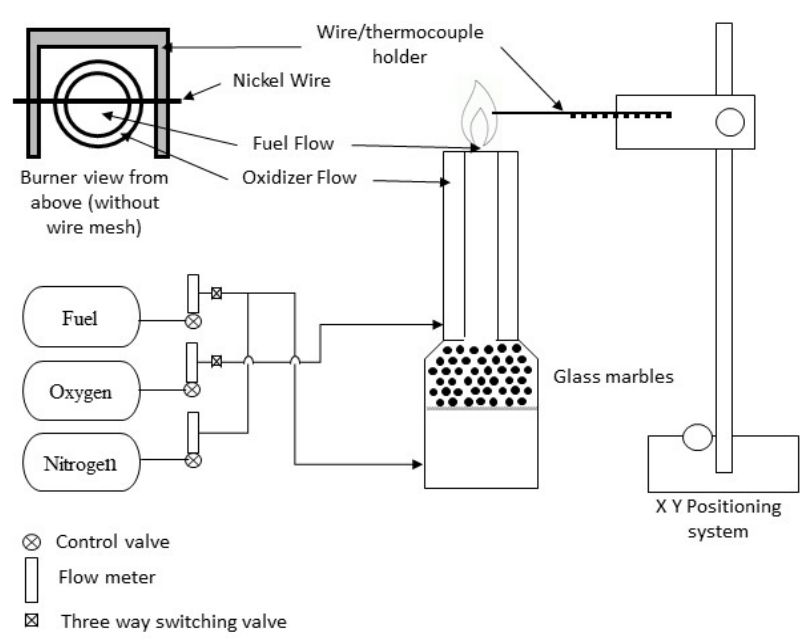

Fig. 1: Schematic diagram of methane co-flow burner with the positioning system.

The $0.4 \mathrm{~mm}$ diameter pure nickel wire (TEMCo Inc.) was cut into $50 \mathrm{~mm}$ length and sonicated for 15 minutes in acetone solution to remove any organic impurities followed by another 15 minutes sonication in distilled water. Next, the cut wires were dipped in nitric acid solution (65\% laboratory grade) which produces a rough surface on the wires. To ensure repeatability of the wires pretreatment process, 10 precut wires were dipped in a new $30 \mathrm{ml}$ nitric acid solution each time. Dipping time of nickel wire in nitric acid was varied to determine the effects of the said parameter toward the formation of CNTs.

The pretreated nickel wires were exposed into the flame via a two-axis positioning system with $1 \mathrm{~mm}$ accuracy. The HAB was varied from 1 to $10 \mathrm{~mm}$. The wire was placed on top of a bespoke holder to ensure minimal disturbance toward the flame as shown in Fig.1. A square $50 \mathrm{~mm}$ stainless-steel wire mesh with $0.4 \mathrm{~mm}$ openings (\#40 mesh, 0.4mm diameter) was placed on top of the substrate wire when the synthesis process was performed to redistribute the flow and increase the flow residence time. 
The materials deposited on top of the nickel wire was directly analyze using field emission scanning electron microscope (FESEM) (Zeiss Crossbeam 340) coupled with Energy dispersive X-ray spectroscopy (EDX) to analyze the surface morphology and elemental composition of the deposited materials respectively. A transmission electron microscopy (TEM) (JEOL JEM-ARM200F) operated at $200 \mathrm{kV}$ was used to analyze structural properties and identify the graphitic properties of the deposited materials. The TEM samples were prepared by dispersing the CNTs in ethanol solution and sonicated for 30 minutes. Drops of the dispersion then placed on top of holey carbon grid and dried.

\section{Flame Synthesis Model}

To simulate the growth of CNTs in the methane co-flow diffusion flame environment, CNT growth rate model is utilized to capture growth parameters in flame scale as well as CNTs growth processes in particles scale. Simulation of the methane flame was done using computational fluid dynamics (CFD). The resolved flame temperatures and carbon composition from the CFD simulation were then used as inputs for the CNT growth rate model at the particle scale. For this study, the co-flow methane flame was modelled using CFD open source tool OpenFOAM based on the work of Mohd Yasin et al.. ${ }^{20}$

Growth rate model that is employed to predict the CNTs growth rate and length in flame was developed based on the modelling study of CNTs growth in CCVD due to the similarities of the CNT growth process in both environment ${ }^{20}$. Hence, using a system of ordinary differential equations (ODE) describing the diffusion of carbon atoms into catalyst nanoparticles, CNT nucleation, and catalyst deactivation, a model that predict CNTs growth rate and length in the flame environment is developed. The main equation that encompasses these growth processes is represented by the ODE in Equation (1) describe the rate change of the surface density of carbon atoms on a catalyst particle. Variables $F_{\mathrm{c} 1}, \tau_{\mathrm{res}}, R_{d, \text { out }}$, and $\emptyset_{c l}$ represent the impingement rate in the unit of atoms per area per second, the residence time of the adsorbed hydrocarbon in the catalyst particles, carbon diffusion rate, and the constant rate of catalyst deactivation via amorphous carbon respectively. The second term represents the formation rate of a stable

$$
\begin{aligned}
\frac{d n_{1}}{d t}=F_{c 1}-\frac{n_{1}}{\tau_{\text {res }}} & -R_{d, \text { out }}-\sigma_{x} D_{s} n_{1} n_{x} \\
& \quad-(i+1) \sigma_{i} D_{s} n_{1} n_{i}-\phi_{c 1}\left(\frac{n_{p 1}+n_{p 2}}{\alpha_{m} n_{m} A_{n p}}\right)
\end{aligned}
$$

cluster. Details of the model and the parameters have been presented elsewhere ${ }^{20}$.

It must be noted that the growth rate model predicts growth of aligned CNTs. However, nature of the co-flow flame which exhibits non-uniform distribution of temperature and species partial pressure produced curly CNTs with random growth pattern as found in our experiment. Nevertheless, the CNT length prediction will be a useful measurement to predict the high growth region within the flame. Due to the non-uniformity of temperature and species mass fraction in the flame environment, multi-scale modelling is applied to study chemical process that happens at different scale ${ }^{21}$. The

$$
L=\left[\frac{1}{a_{c} C^{*}} \sqrt{\frac{D_{b}}{\pi}}\right] \times \int_{0}^{t} \frac{n_{1}}{\sqrt{t}} d t
$$

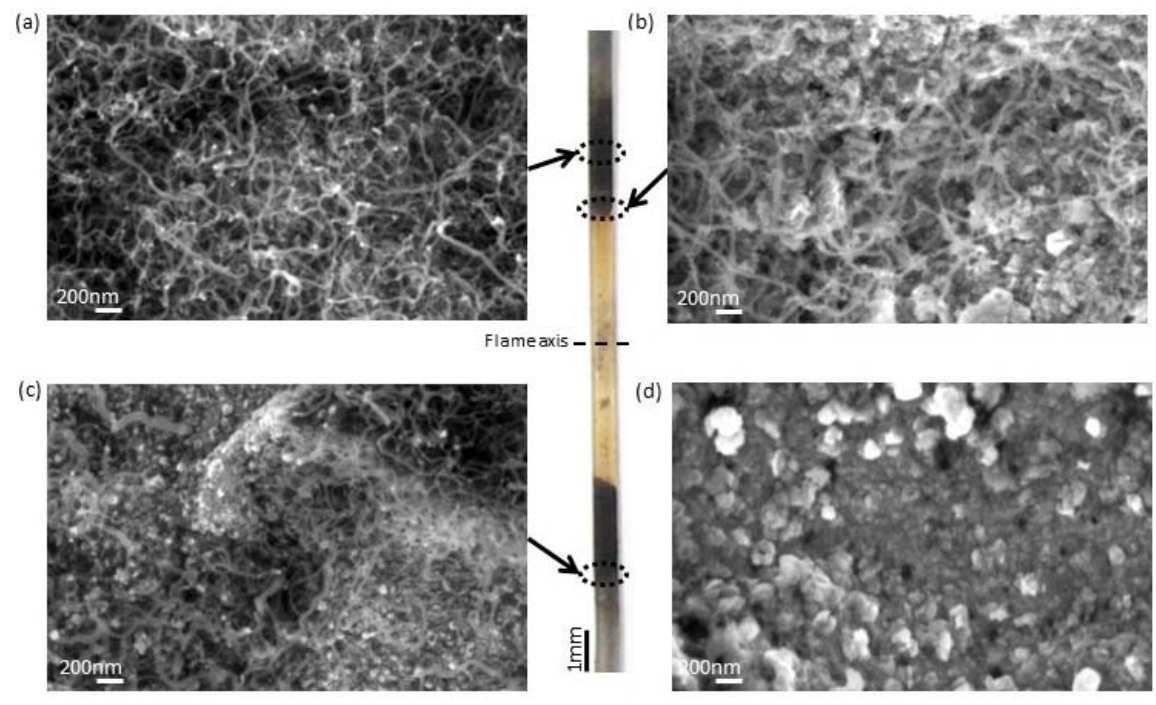

Fig. 2: (a) - (d) are SEM images of deposit found on the pure nickel wire dipped in nitric acid for 165 seconds and exposed in methane co-flow diffusion flame at $6 \mathrm{~mm}$ HAB for 10 minutes. (a) At the middle of the deposit region, (b) the inner edge of deposit region, (c) the outer edge of deposit region, and (d) similar location as (a) but for nickel wire without nitric acid pretreatment. 
multi-scale model incorporated arrays of temperature and species mass fraction, rather than a single uniform value of the said parameters ${ }^{20}$. The solution of carbon density from Equation (1) was used to calculate the length and growth rate of CNT using Equation (2). The constants $a_{c}$, $D_{b}$, and $C^{*}$ represents the diameter, carbon bulk diffusivity through nickel, and the amount of carbon atoms required for the formation of a carbon monolayer respectively ${ }^{20}$.

\section{Result and Discussion}

Fig. 2 shows the nickel wire with deposit after being exposed to flame environment across the flame axis as indicated. The CNTs that are grown in the middle section of the growth region are curly and grow in random formation as shown in Fig.2 (a). The diameter of the CNTs are varied between 9 to $27 \mathrm{~nm}$. This variation is due to the myriad of catalyst nanoparticles of varying shapes and sizes produced on top of the nickel wire due to carbide-induce breakup process as shown in Fig.2 (d) ${ }^{28}$. Fig.2 (b) and (c) show SEM images at the outer and inner edge of the growth region respectively. At the outer edge, near to the high temperature region, the morphology of the formed CNTs is nearly similar with that of the middle section, with long curly CNTs that experience the disorganized growth, however with much less density and a significant number of large particles on the wire surface. Similarly, at the inner edge of the growth region, the CNTs have a similar characteristic with less density with presence of large particles on the surface of the wire.

Fig. 3 shows the TEM images of the CNTs hollow tube structure with an average diameter of $25 \mathrm{~nm}$. The CNTs are entangled and disarray with different curvatures and bends. The sampled CNT is multiwalled with lattice distance approximately $0.3 \mathrm{~nm}$ obtained from gray scale profile analysis. In Fig.3, the solid nanoparticle can be observed in the TEM image at the end cap of the tube indicating the tip growth mechanism. These nanoparticles are nickel oxides as identified by separate EDX analysis.

In the present work, the observation on the effect of

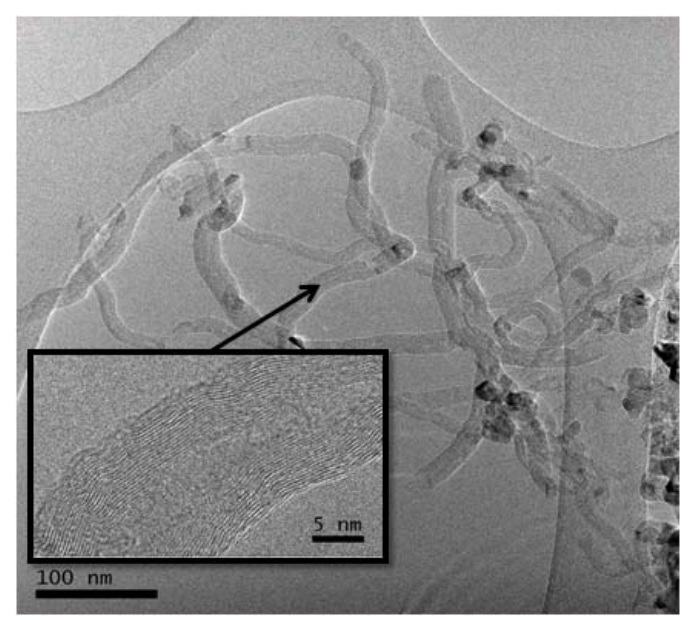

Fig. 3: TEM image of the synthesized CNTs acid dipping duration and HAB toward the formation of the CNTs was based on the measurement of CNTs growth region on top of the wire. The CNTs growth region were identified through SEM images analysis at various spots on top of the flame-exposed wires. It was observed that CNTs growth regions were indicated by the dark surface on top of the wires due to complete coverage of the wire surface by CNTs and amorphous carbon layer as shown in Fig.2 (a). Measurement of CNTs growth region did not include the grey colored region at its edges where the CNTs grow sporadically as shown in Fig.2 (b) and (c).

The HAB and the exposure time was fixed at $6 \mathrm{~mm}$ and 10 minutes respectively to analyze the effect of acid dipping duration toward the formation of the CNTs on the pure nickel wire. The nickel wires were dipped in nitric acid in 15 seconds increment. As shown in Fig.4, CNTs is not produced when the wires were dipped in acid for less than 90 seconds. CNTs are produced only with wire that dipped in for at least 90 seconds, up to 210 seconds. The nickel wire that is dipped in nitric acid for 165 seconds produces the longest CNTs growth region around $4 \mathrm{~mm}$. Whereas minimal CNTs deposit region can be observed on both wires dipped for 90 seconds and 210 seconds. The total area of CNTs growth lengthwise on the wires increases as the wire dipped longer than 90 seconds up to 165 seconds. Beyond 165 to 210 seconds, the total growth area of CNTs decreases gradually. Wires dipped beyond 210 seconds do not produce any observable deposit. At the highest growth region, the CNT deposit blanketed the wire around $2 \mathrm{~mm}$ lengthwise on the fuel side, away from the highest flame temperature region. However, the deposit area did not include the region near to the flame axis. Acid dipping duration only affect the growth region but not the density of the CNTs.

To analyze the effect of HAB toward formation of CNTs, only wires dipped in nitric acid for 165 seconds were used in this analysis. With the exposure time fixed to 10 minutes at each $\mathrm{HAB}$, the wire was placed from

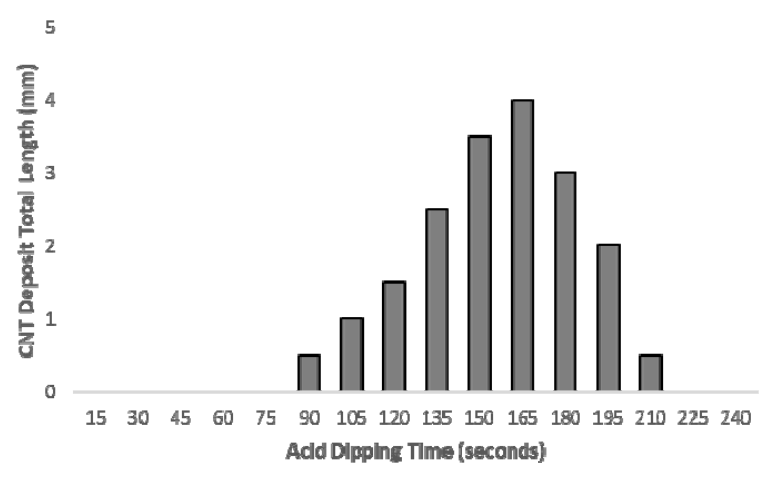

Fig. 4: CNT deposit region total length for nickel wires at different acid dipping period. $\mathrm{HAB}$ and exposure time fixed at $6 \mathrm{~mm}$ and 10 minutes respectively. 


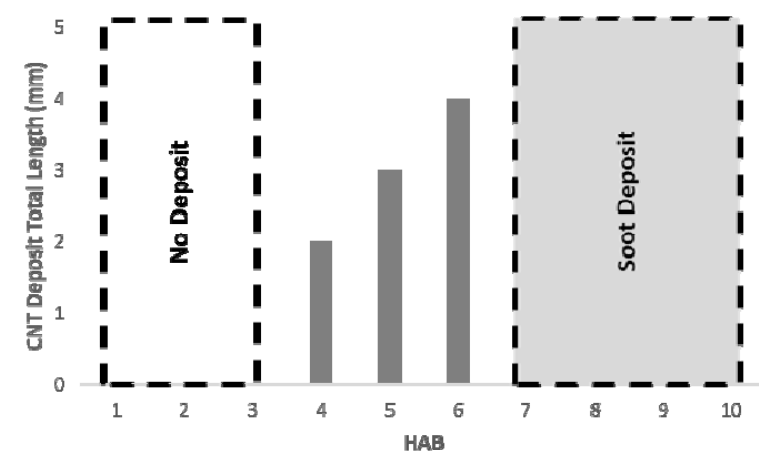

Fig. 5: CNT deposit region total length at different HAB using nickel wire dipped in acid for 165 seconds

$1 \mathrm{~mm}$ up to $10 \mathrm{~mm} \mathrm{HAB}$. The test stopped at $10 \mathrm{~mm}$ due to the clear presence of soot formation on the wire.

Fig.5 shows total length of CNTs growth region at various HAB using wire dipped in acid for 165 seconds. As the HAB increases from 1 to $3 \mathrm{~mm}$, no dark spot can be observed on top of the wire. However, at $4 \mathrm{~mm}$, minimal CNT deposit can be observed at the similar region where the deposit observed at $6 \mathrm{~mm} \mathrm{HAB}$. Nevertheless, the overall length of the deposit area at $4 \mathrm{~mm}$ HAB was only $2 \mathrm{~mm}$, which is shorter than $4 \mathrm{~mm}$ which is observed at $6 \mathrm{~mm}$ HAB. As the HAB increases to $5 \mathrm{~mm}$, the length of the CNT growth region increases to $3 \mathrm{~mm}$. Interestingly, $7 \mathrm{~mm} \mathrm{HAB}$ did not produce any CNTs but a thick deposit of soot. This soot formation can be observed up to $10 \mathrm{~mm}$ HAB with the region of soot deposit increases with the increase of HAB.

SEM images in Fig.6 (a) to (d) show the surface condition of the nickel wire with and without acid pretreatment before exposure to the flame. Without acid pretreatment, the surface of the wire was relatively smooth with some obvious crevasse on the surface due to the fabrication defects as shown in Fig.6 (a). As the wire dipped in nitric acid for 90 seconds, a wavy surface is formed as shown in Fig.6 (b). This wavy surface is relatively similar to the wire dipped for 210 seconds as shown in Fig.6 (d). Theoretically, the increase in surface roughness of the wire enhanced the tendency for formation of CNTs on the surface ${ }^{1}$. The wire dipped in nitric acid for 165 seconds, however, has much more straight edges and crevasse. It can also be seen that there was the formation of nickel oxides nanoparticles on the surface which becomes the catalyst to the formation of the CNTs. Unfortunately, high magnification SEM analysis was disturbed due to high magnetic field from $\mathrm{Ni}$ wire resulting in inevitable distortions.

Nickel wire without pretreatment is unable to produce CNTs in methane flame due to the absence of suitable catalyst nanoparticles that could initiate formation of CNTs. Suitability of the catalyst nanoparticles depends on two factors; type and size ${ }^{1}$. In this experiment, pure nickel was used as it has been proven to be one of the transitional metals that has a suitable characteristic as a catalyst for CNT formation, such as high carbon solubility, high diffusion rate, and has a relatively low melting temperature. Furthermore, CNTs growth has been (a)

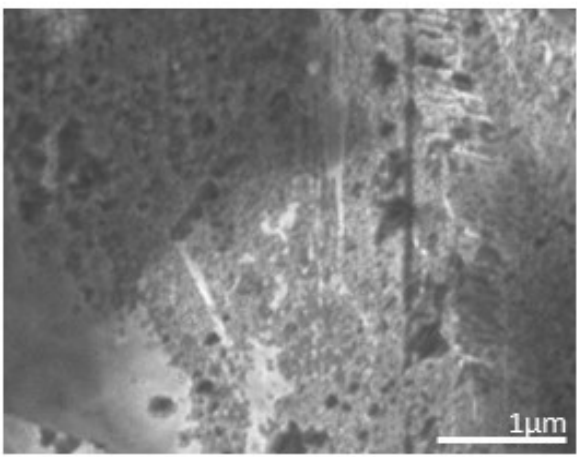

(c)

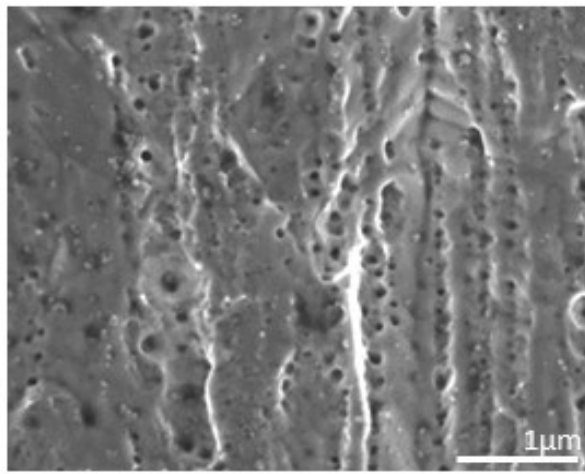

(b)

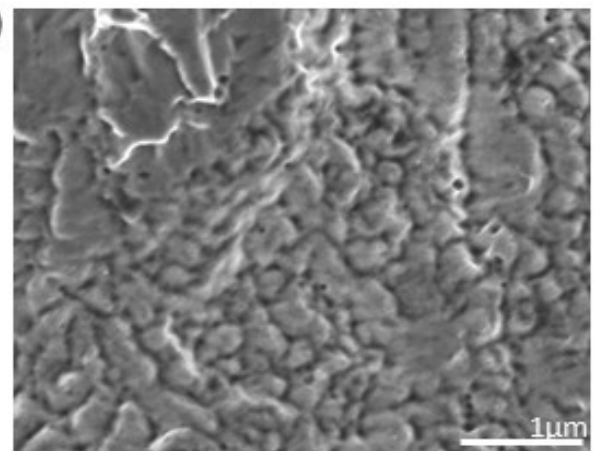

(d)

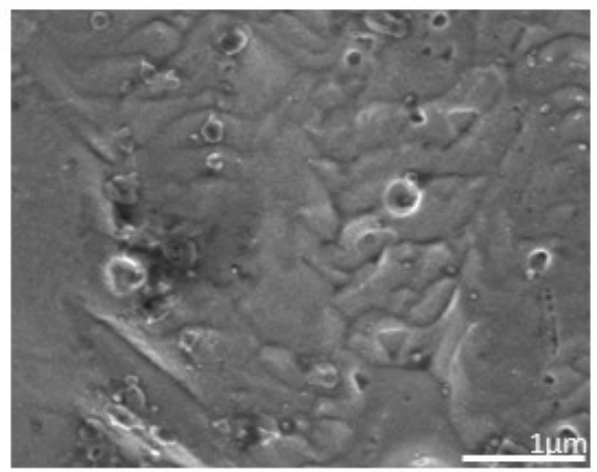

Fig.6: SEM images of pure nickel wire surface pre-treated with nitric acid for (a) 0 seconds (b) 90 seconds (c) 165 seconds (d) 210 seconds 


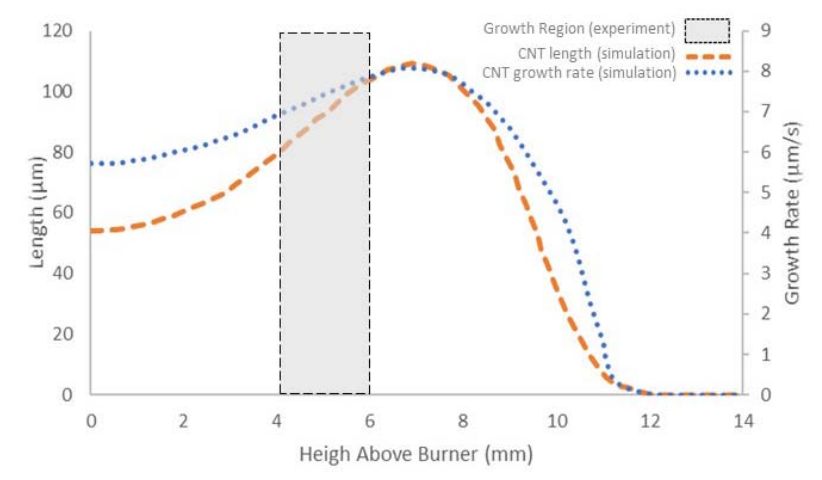

Fig.7: Results of the coupled CFD-particles scale simulation for predicted CNT length and growth rate at different $\mathrm{HAB}$. The peaks that represent maximum CNTs growth

proven on pure nickel nanoparticles or nickel oxides ${ }^{29}$. Hence, only the size factor plays a key role in determining the inception and growth of CNTs in this experiment. Inception and growth of MWNTs are known to occur on catalyst nanoparticles less than $100 \mathrm{~nm}$, while SWNTs only grow on catalyst sized between 4 to $8 \mathrm{~nm}$ in CCVD environment ${ }^{30}$. SEM analysis of the deposited nickel wire exposed in the flame without pretreatment shows the presence of numerous nickel nanoparticles with diameter larger than $100 \mathrm{~nm}$, which inhibit CNT formation as shown in Fig.2 (d) ${ }^{31}$.

\subsection{Simulation Result}

Fig.7 shows results of predicted CNTs growth rate and length for the simulated co-flow methane flame using nickel oxide as catalyst. The highest growth rate located at the similar location of the longest CNT produced at approximately $7 \mathrm{~mm}$ HAB which approximately correlates with the location of highest CNT deposit region in the experiment. The multi scale model was unable to predict HAB that did not produce any deposit or produces soot due to exclusion of soot modelling in the present study. Overall, the model shows positive initial result and a clear prospect to be further developed to help predict CNTs growth in co-flow flame or other flame configurations.

\section{Conclusion}

High density of MWNTs has been successfully synthesized directly on top of oxidized pure nickel wire in methane co-flow diffusion flame. The pure nickel wire was oxidized by dipping the wire in nitric acid for certain period. The optimum synthesis process occurred for 10 minutes with the pre-treated pure nickel wire placed inside the flame at $6 \mathrm{~mm}$ HAB. The amount of CNTs growth region on the wire was varied according to the duration of wires dipping in the nitric acid. The highest CNTs growth region on the wire occurred at 165 seconds dipping time, while 90 seconds is the minimum time required for the wire to be oxidized in nitric acid for it to be able to produce CNTs. With a longer period of exposure to nitric acid, the pre-treated wire did not produce any CNTs once the wire was exposed more than 260 seconds. CNTs were only produced in narrow window of HAB, from $4 \mathrm{~mm}$ to $6 \mathrm{~mm}$. Prediction of the CNT growth region using multi-scale modelling method achieve a reasonable agreement with the experimental results though the region of no growth was not reproduced due to the exclusion of soot modelling.

\section{Acknowledgements}

This research was funded by the Research University Grant (GUP) Q.J130000.2524.17H28 awarded by Universiti Teknologi Malaysia (UTM) and the Fundamental Research Grant Scheme (FRGS) R.J130000.7824.4F829 awarded by the Malaysian Ministry Education.

\section{References}

1) N. Hamzah, M. F. M. Yasin, M. Z. M. Yusop, A. Saat and N. A. M. Subha, J. Mater. Chem. A, 5, 25144-25170 (2017)

2) C. M. Seah, S. P. Chai and A. R. Mohamed, Carbon, 49, 4613-4635 (2011).

3) C. J. Unrau, R. L. Axelbaum and C. S. Lo, J. Phys. Chem. C, 114, 10430-10435 (2010).

4) S. Moore, Global carbon nanotube market to grow to around 4000 tonnes by 2023, PlasticToday.com (2019).

5) H. Hong, N. K. Memon, Z. Dong, B. H. Kear and S. D. Tse, Proc. Combust. Inst., 37, 1249-1256 (2019).

6) S. Okada, H. Sugime, K. Hasegawa, T. Osawa, S. Kataoka, H. Sugiura and S. Noda, Carbon, 138, 1-7 (2018).

7) L. Zheng, C. Bao, S. Lei, J. Wang, F. Li, P. Sun, N. Huang, L. Fang and X. Sun, Carbon, 133, 423-434 (2018).

8) Y. Sun, B. Sun, Z.-Z. Kang, Y.-H. Guo and X.-W. Jia, Mater. Res. Express. 5, 055024 (2018)

9) S. Suzuki and S. Mori, Chem. Eng. Sci., 186, 62-73 (2018).

10) O. Padilla, J. Gallego and A. Santamaría, Diam. Relat. Mater., 86, 128-138 (2018).

11) S. Suzuki and S. Mori, Diam. Relat. Mater., 82, 79-86 (2018).

12) T. Zhao, X. Li and H. Yan, Combust. Flame, 196, 108-115 (2018).

13) Y. Guo, G. Zhai, Y. Ru, C. Wu, X. Jia, Y. Sun, J. Yu, Z. Kang, Y. Guo, G. Zhai, Y. Ru, C. Wu, X. 
Jia and Y. Sun, AIP Adv, 8, 1-11 (2018).

14) L. Yuan, K. Saito, C. Pan, F. A. Williams and A. S. Gordon, Chem. Phys. Lett., 340, 237-241 (2001).

15) L. Yuan, T. Li and K. Saito, Carbon, 41, 1889-1896 (2003).

16) T. X. Li, K. Kuwana, K. Saito, H. Zhang and Z. Chen, Proc. Combust. Inst., 31, 1855-1861 (2009).

17) S.-S. Hou, K.-M. Chen, Z.-Y. Yang and T.-H. Lin, Materials, 8, 4805-4816 (2015).

18) J. Z. Wen, M. Celnik, H. Richter, M. Treska, J. B. Vander Sande and M. Kraft, J. Mater. Chem., 18, 1582 (2008).

19) K. Kuwana and K. Saito, Carbon, 43, 2088-2095 (2005)

20) M. F. M. Yasin, M. T. Zainal, M. A. Wahid, Mater. Res. Express, 3, 105040 (2016).

21) D. M. Abouelella, S.-E. K. Fateen and M. M. K. Fouad, Evergreen, 5, 43-51 (2018).

22) H. Endo, K. Kuwana, K. Saito, D. Qian, R. Andrews and E. A. Grulke, Chem. Phys. Lett., 387, 307-311 (2004).

23) W.-C. Hu, S.-S. Hou and T.-H. Lin, J. Nanosci. Nanotechnol., 14, 5363-5369 (2014).

24) S. S. Hou, D. H. Chung and T. H. Lin, Carbon, 47, 938-947 (2008).

25) L. Yuan, T. Li and K. Saito, Proc. Combust. Inst., 29, 1087-1092 (2002).

26) T. X. Li, H. G. Zhang, F. J. Wang, Z. Chen and K. Saito, Proc. Combust. Inst., 31, 1849-1856 (2007).

27) F. Xu, H. Zhao and S. D. Tse, Proc. Combust. Inst., 31, 1839-1847 (2007).

28) N. K. Memon, F. Xu, G. Sun, S. J. B. Dunham, B. H. Kear and S. D. Tse, Carbon, 63, 478-486 (2013).

29) C. J. Unrau, R. L. Axelbaum and P. Fraundorf, $J$. Nanoparticle Res., 12, 2125-2133 (2010).

30) R. L. Vander Wal and T. M. Ticich, J. Phys. Chem. B, 105, 10249-10256 (2001).

31) R. L. Vander Wal, G. M. Berger and L. J. Hall, $J$. Phys. Chem. B, 106, 3564-3567 (2002). 